\title{
On Selection and Optimal Design of Cogeneration Units in the Industrial Sector
}

\author{
Marco Gambini', Michela Vellini*2 \\ ${ }^{1}$ Department of Industrial Engineering, University of Rome Tor Vergata, Via del Politecnico, 1, \\ Rome, Italy \\ e-mail: gambini@ing.uniroma2.it \\ ${ }^{2}$ Department of Industrial Engineering, University of Rome Tor Vergata, Via del Politecnico, 1, \\ Rome, Italy \\ e-mail: vellini@ing.uniroma2.it
}

Cite as: Gambini, M., Vellini, M., On Selection and Optimal Design of Cogeneration Units in the Industrial Sector, J. sustain. dev. energy water environ. syst., 7(1), pp 168-192, 2019, DOI: https://doi.org/10.13044/j.sdewes.d6.0236

\begin{abstract}
In Europe, the introduction of high-efficiency cogeneration regulatory has radically changed the incentive scheme for cogeneration power plants that, in turn, inevitably affected the evaluation of techno-economic feasibility of new cogeneration plants. In this regard, selection and optimal design for cogeneration systems need to be investigated in the light of the new regulatory context. The first objective of this paper is an in-depth characterization of crucial industrial sectors aiming to define their average specific electric and thermal energy consumption, in addition, a detailed characterization of each cogeneration technology is provided, so as to identify the most significant cogeneration performance. Then, based on both energy requests of industrial processes and cogeneration performance, a specific procedure is applied to each of the analysed technology for a proper selection and design of a cogeneration system within the new high-efficiency cogeneration regulatory context. Finally, a total key performance indicator has been defined with the purpose to choose the technology best suited to a specific application so that the optimal solution can be immediately identified among a variety of possible ones. The result of this work represents an objective proposal of cogeneration technologies for different industrial processes application as a function of their energy requirements and production.
\end{abstract}

\section{KEYWORDS}

High-efficiency cogeneration, Primary energy saving, Electricity from cogeneration, Net present value, Pay back period, Carbon dioxide emissions avoided.

\section{INTRODUCTION}

Combined Heat and Power (CHP) production is a good energetic practise, it allows for attaining:

- High overall efficiencies;

- Primary energy savings in comparison with separate production of the same heat and power;

\footnotetext{
* Corresponding author
} 
- Pollutant emission reductions [especially Carbon dioxide $\left(\mathrm{CO}_{2}\right)$ emissions] in comparison with separate production of same heat and power.

Obviously, feasibility of a CHP system depends on heat required by a final user: actual profit of CHP can become not so favourable if there are inconsistencies between heat produced by a CHP system and heat required by a final user (in terms of quality and/or quantity of heat), or if there is big distance between heat production site and heat use site [1].

For all these reasons, CHP is largely implemented worldwide. Heat is used in industrial sectors, residential heating and commercial and public services. World energy balance [2] states that in 2015 heat produced by power stations was 306 Mtoe (excluding statistical differences), this heat, together with 2 Mtoe from other heat productions, was used in residential heating, commercial and public services (137 Mtoe), industries (124 Mtoe) and own use (37 Mtoe).

Havelský [3], among others, observed a difficulty in evaluating the efficiency of CHP units already in 1999, therefore, an accurate regulation of such plants had to be created: this led to the European Directive 2004/8/CE.

Given the energy and environmental benefits of CHP, this technological practise is generally encouraged through national incentive programs based, in turn, on performance parameters. Generally, the best performance parameter to evaluate a CHP system is the Primary Energy Saving (PES), however, since two different useful effects are produced (power and heat), in different values, incentive programs may favour one effect more than the other. For instance, if an incentive program encourages a CHP system, that achieves a threshold value of PES, to sell favourably all electricity produced, it is obvious that this CHP system will be sized to produce, besides heat required by the final user, the maximum possible electricity. Vice versa, if an incentive program encourages a CHP system, which achieves a threshold value of PES, to produce electricity and heat so that it attains a threshold value of overall efficiency very high, it is obvious that this CHP system will be sized to produce the maximum possible heat for the final user. Finally, threshold value of PES is another relevant aspect that influences type, size and operating mode of a CHP system.

In Italy, starting from 1 January 2011, with the adoption of the European Directives on High-Efficiency Cogeneration (HEC), the incentive scheme for cogeneration power plants has changed radically, consequently, boundary conditions, both for the evaluation of techno-economic feasibility of new cogeneration plants in different areas of application (industry, service, residential, etc.) and for the optimal operation of existing plants, have transformed in turn. In detail, the previous legislation considered the entire electricity production as cogeneration electricity if two parameters, primary energy saving and thermal limit, evaluated on an annual level exceeded specific limit values. According to this previous incentive program, the Italian cogeneration power plants were sized to produce the maximum possible electricity, an analysis conducted by authors $[4,5]$ showed that, up to 2013 :

- About $50 \%$ of the useful heat produced by cogeneration plants was produced by combined gas and steam power plants;

- The same combined power plants produced approximately $80 \%$ of the total electricity produced in cogeneration;

- No types of cogeneration power plants were able to reach the limit value for efficiency required by the current regulation, except for steam power plants equipped with backpressure turbine.

Having regard to Directive 2004/8/CE, introducing at European level HEC, and to Directive 2012/27/UE (abrogating the previous one), if cogeneration power plants do not reach an established value in terms of the overall efficiency it is necessary to subdivide them in a CHP portion and a non-CHP portion with incentives proportional to the energy 
quantities pertaining to CHP portion only, and, in particular, to the heat produced by such portion. This situation implies that, contrary to what happened in the past, the advantage of a cogeneration power plant is higher the more it is designed on the basis of the thermal demand of users.

In the framework of European Cogeneration Directives, some authors analysed the opportunity to install new, small-scale and micro-cogeneration systems [6]. Other authors provided procedure for the calculation of performance indicators in the context of HEC, giving also specific hints for future revision of the Directive on Cogeneration and the related texts [7]. Other authors, in particular Gvozdenac et al. [8], evaluated the impact of a changeable practical operating mode and the sensitivity of the referred efficiency and of the power loss coefficient to the attractiveness of cogeneration. The power loss coefficient $(\beta)$ quantifies the fraction of the electric energy not produced in favour of heat and its calculation appears to be a critical aspect of the implementation of the Directive, Gvozdenac's work investigated the influence of such parameter on CHP electricity and CHP fuel energy, stating that this factor, along with the referred efficiency, is crucial in assessing a plant's profitability, coming to the proposal of a modified method for the evaluation of a CHP plant's efficiency, in line with the work of Urošević et al. [9].

In previous papers, authors focused their attention on the European HEC regulatory framework. In particular, in [10], the transposition of the Directive 2004/8 EC in the Italian context, referring to the procedure indicated in ministerial guidelines for dealing with cogeneration, was studied, subsequently, in [11], issues relating to the HEC regulatory framework, to power plant classification and to the general calculation procedures of cogeneration performances for the most representative industrial cogeneration plant types were dealt with, especially discussing the effects of the power loss coefficient on CHP electricity and power-to-heat ratio. That was an opportunity to better explain the procedure to evaluate plants in a HEC framework and set up for the evaluation of their primary energy savings, in a similar fashion as the studies carried out by Kanoglu and Dincer [12]. The above works were well aligned with the literature of the sector: for example, Verbruggen [13] identified several weak points in the EU Directive, addressing its incompleteness in quantifying the CHP activity of a plant and its resorting to average default values to compensate for the lack of reliable data on the particular CHP activity of particular European plants. To substantiate these concerns, interested stakeholders elaborated a procedure, published as manual, more accurately quantifying CHP activities on the basis of direct measurement of cogeneration heat. Verbruggen himself showed a method able to remedy this weakness and improving transparency, based on the measurement of non-recoverable losses and condensing heat rather than adopting fixed values for the threshold efficiency. Verbruggen [13] also put his proposed modification in practice by applying it to steam cycles. Given the efficacy and the fairness of his method, he achieved the result of laying of the foundations for public regulations following the principles of optimal specificity, thus showing EU regulation's flaws.

According to Monni and Raes [14], the CHP Directive is one of the relevant policies contributing to the mitigation of energy consumptions and $\mathrm{CO}_{2}$ emissions, it was successfully implemented in Finland, reaching, already in 2006, the values of $90 \%$ of heat and 78\% of electricity produced by CHP in Helsinki. Al-Mansour and Kožuh [15] elaborated a risk model to approach decision-making processes when investing in CHP. The result of the application of the procedure established by the Directive led to the highlighting of the heavy dependence of payback period and internal rate of return on fuel price. A significant reduction in emissions can be devised also in the field of trigeneration. Li et al. [16] highlighted the relevance of CHP systems in reducing pollutant emissions for hotels, offices and residential buildings when used as air 
conditioning devices. The ability of cogeneration (and trigeneration) to reduce energetic costs was also ascertained by Cho et al. [17], who provided an in-depth overview of CHP systems and optimization strategies.

Other researchers also noted the capability of well-regulated cogeneration to promote innovative energy scenarios. For instance, Ropenus et al. [18] shed light on the capability of CHP (and the related regulations) to encourage distributed generation.

Besides, CHP plants can be provided with an operation manager for better functioning; in this way they become able to make use of fluctuating Renewable Energy Sources (RES) and, inevitably, much more attractive. A study of such a management approach has been conducted by Wolfrum et al. [19]. An example of RES coupling was studied by Uday Kumar et al. [20] in their work regarding solar cogeneration systems for hot water production. Their experimental analysis showed that solar cogeneration systems increase economic profitability, but a substantial improvement in terms of efficiency is possible only in a configuration making use of both direct solar and thermal store integration. Solar cogeneration systems were discussed also by Boyaghchi et al. [21]. They applied well-known Specific Exergy Cost (SPECO)-based thermoeconomic analysis to study a solar micro-Combined Cooling Heating and Power (CCHP) integrated with Organic Rankine cycle (ORC). The multi objective optimization indicated that the efficiency of such a system strongly decreases in winter, displaying a reduction of 24 percentage points with respect to summer. A similar research was carried out by Calise et al. [22], who performed dynamic simulations in TRNSYS environment about a solar field virtually located in Naples (Southern Italy) producing heat for a variable inlet temperature ORC equipped with a gas-fired auxiliary heater. The study emphasized the capability of this system of producing electricity and space heating all year long, keeping efficiency high, even with a significant reduction in winter.

CHP is also suited to supplying energy to microgrids [23].

Concerning optimization strategies, Hajabdollahi et al. [24] designed a new operational strategy called Variable Electric cooling Ratio (VER) and evaluated it through a method based on Particle Swarm Optimization (PSO) algorithm and an objective function termed as relative annual benefit: results showed that VER strategy proved to be more beneficial than traditional strategies in all climates.

This paper, instead, provides new optimal design criteria for cogeneration plants operating in industrial sectors within the HEC framework. First, an in-depth characterization of crucial industrial sectors is defined in order to assess the average specific consumption of electric and thermal energy of the diverse production processes. Then, a detailed characterization of cogeneration systems, having regard to the HEC regulatory context, is provided so as to identify the main cogeneration performance of each technology. Then, by knowing energy requests of the industrial processes taken into account and cogeneration performance of the main technologies herein analysed, a specific procedure is applied in order to choose and design a cogeneration system, according to the new regulatory context. Finally, with the aim of identifying the technology most suited to the specific application, a Total Key Performance Indicator (TKPI), has been defined so that the optimal solution, among a variety of possible ones, can be immediately selected. If two solutions have a very similar TKPI, the proposed method allows to evaluate in which field such solutions show the best performance (as in energy, economic or environmental performance). It is worth mentioning that, in this paper, thermal and electric load profiles of a specific production process are not taken into consideration since the objective of the paper is to suggest the best technology for an industrial process and define its optimal size. Performance evaluation in the actual operation mode of a specific production process is out of the scope of this paper and it is worthy of consideration only if actual operational data become available. 


\section{THE USE OF COGENERATIONIN INDUSTRIAL SECTORS}

This section describes the industrial processes and the cogeneration systems analysed further in this paper. More specifically, first, on the basis of a previous detailed analysis regarding specific consumption (electrical and thermal) of the main industrial processes, ten classes of production processes are identified and characterised. Then, the configuration of the analysed cogeneration systems and their main input data are illustrated, finally, using these data, parametric analyses have been carried out aimed to deduce effective CHP parameters used in these evaluations.

\section{Characterisation of main industrial processes relevant in cogeneration field}

Industry facilities have every interest in providing themselves with CHP units. However, an optimization of such units for industry applications is needed and represents an issue frequently addressed by research. Wang et al. [25] optimised the performance of different cogeneration plants to be employed in the cement industry, in order to recover exhaust heat. Monte et al. [26] analysed different paper industry production processes, proposing for each of them, technical solutions aimed at increasing the overall efficiency. Cogeneration systems are the most suitable approach, as also noted by Posch et al. [27], who analysed the Austrian case and ascertained that energy costs must be minimized as they are the main factor affecting energy management. Tamburini [28] et al. discussed the upgrading of a multiple effect distillation along with thermal vapour compression desalination plant, comparing steam plant-based solutions differing for the steam extraction pressure. They performed an evaluation based on the current European legislation and came at the conclusion that the amount of CHP electricity increases almost linearly with the number of supplied distillation units, however, they expressed the concern that the primary energy savings are strongly affected by the chosen referred efficiency values.

With regard to industry and cogeneration in Italy, an in-depth characterisation of industrial sectors, significant in CHP field, has been conducted, in order to define specific electrical and thermal consumptions of their production processes. Such a characterisation has been carried out by consulting the most trusted databases related to this field with reference to Italy only:

- Paper mills [29];

- Glass industry [30];

0 within both the Italian and European context:

- Food, drink and milk industry [31-33];

- Ceramic manufacturing industry [34, 35];

- Refining of oil and gas [36, 37];

$\circ$ and also taking into account a global framework:

- Iron and steel $[38,39]$;

- Rubber and plastic industry [40];

- Other relevant industries [41].

Actual data used to derive this characterization were acquired from Gestore dei Servizi Energetici (GSE), the state-owned company that promotes and supports RES in Italy. Finally, information owned by authors, deduced by activities previously conducted in different industrial sectors, was also reworked for this purpose.

Based on these data, the most interesting production processes have been identified, evaluating the specific energy consumption for each individual stage of the single process as well as for the whole production process.

With reference to the purpose of this paper, which is not going to look in detail at an individual industrial sector relevant for HEC purposes, but rather to provide energy and economic information on HEC applicable technologies, four classes of industrial processes have been defined, characterized by the same heat to electricity ratio $(H / E)$. 
In each class, there are more industrial processes (Table 1), characterised by different specific thermal $\left(C_{\mathrm{s}, \mathrm{H}}\right)$ and thus electric demand $\left(C_{\mathrm{s}, \mathrm{E}}\right)$, therefore, these 10 categories are representative of different industrial sectors. Food sector is present in many categories because, in this field a great number of products, also very different from each other, can be made. Yarn, paper and pharmaceutical industries are the industrial sectors with the highest amount of heat demand.

Table 1. Average thermal and electric consumption of characteristic industrial sectors

\begin{tabular}{cccccc}
\hline & & $\begin{array}{c}\text { Heat/electricity } \\
(H / E)\end{array}$ & $\begin{array}{c}C_{\mathrm{s}, \mathrm{E}} \\
{[\mathrm{kWh} / \mathrm{ton}]}\end{array}$ & $\begin{array}{c}C_{\mathrm{s}, \mathrm{H}} \\
{[\mathrm{kWh} / \mathrm{ton}]}\end{array}$ & Possible sector \\
\hline \multirow{2}{*}{ Class 1 } & CHP-1 & 0.5 & 50 & 25 & Wood \\
& CHP-2 & 0.5 & 400 & 200 & Glass/iron\&steel \\
\hline \multirow{4}{*}{ Class 2 } & CHP-3 & 1.0 & 100 & 100 & Food/ceramics \\
& CHP-4 & 1.0 & 750 & 750 & Chemical/food \\
& CHP-5 & 1.0 & 1,300 & 1,300 & Yarn/leather \\
& CHP-6 & 1.0 & 3,000 & 3,000 & Pharmaceuticals/yarn \\
\hline \multirow{3}{*}{ Class 3 } & CHP-7 & 2.0 & 50 & 100 & Food/coke oven \\
& CHP-8 & 2.0 & 250 & 500 & Food \\
& CHP-9 & 2.0 & 750 & 1,500 & Paper \\
\hline Class 4 & CHP-10 & 3.0 & 80 & 240 & Refineries \\
\hline
\end{tabular}

\section{Characterisation of main industrial cogeneration technologies}

In $[10,11]$, numerical assessments were performed in order to determine HEC performances of different power plant solutions. Such evaluations have been further examined in this paper and a summary of results elaborated for the evaluation of the installable power plants according to the particular industrial sector. The following technologies have been taken into consideration:

- Internal combustion engines (ICE): In a cogeneration setup, they are characterised by a power loss factor by heat extraction at a steam turbine $(\beta)$ equal to 0 and efficiency of non-combined electrical/mechanical energy generation $\left(\eta_{\text {non-CHP,E }}\right)$, equal to electric efficiency $\left(\eta_{\mathrm{E}}\right)[10,11]$. It seems important to remember that $\beta$ must be calculated only for steam condensing extraction turbine-based plants, indeed it gives the electricity loss due to steam extraction for heat. In the simulations conducted in this study, a heat recovery from exhaust gases of the engine and water/oil circuit has been considered, heat is provided as steam, generated by hot fluids from ICE, at a variable temperature between $150{ }^{\circ} \mathrm{C}$ and $300{ }^{\circ} \mathrm{C}$ (heat from water/oil circuit is used for the first part of water economization). Main energy parameters ( $E_{\mathrm{CHP}} / E, F / E$ and $\left.\mathrm{PES}\right)$ have been deduced: such parameters refer to two power plant types, corresponding to small size power plants (SS, Small Size, around $1 \mathrm{MWe}$ ) and large size power plants (LS, Large Size, around $15 \mathrm{MWe}$ ), respectively. Numerical investigation has been conducted by varying $H_{\mathrm{CHP}} / E$ ratio, recovering progressively more heat from the exhaust gases of the engine, all the way to a minimum limit value established for gas temperature at heat recovery system outlet (about $90^{\circ} \mathrm{C}$ );

- Gas turbines (GT): In a cogeneration setup, much like ICE's, they are characterised by $\beta=0$ and $\eta_{\text {non-CHP,E }}=\eta_{\mathrm{E}}$. In the simulations, a plant configuration made up of a gas turbine and a Heat Recovery Steam Generator (HRSG), fed by exhaust gases from the gas turbine, has been considered, indeed heat is provided as steam at a variable temperature between $150{ }^{\circ} \mathrm{C}$ and $300{ }^{\circ} \mathrm{C}$. Main energy parameters $\left(E_{\mathrm{CHP}} / E\right.$, $F / E$ and PES) have been deduced: such parameters refer to two power plant types, corresponding to small size power plants (SS, Small Size, around $5 \mathrm{MWe}$ ) and large 
size power plants (LS, Large Size, around $30 \mathrm{MWe}$ ), respectively. Numerical investigation has been conducted by varying $H_{\mathrm{CHP}} / E$ ratio, recovering progressively more heat from exhaust gases, up to a minimum limit value established for gas temperature at heat recovery system outlet (about $90^{\circ} \mathrm{C}$ );

- Steam Power Plants with Backpressure Turbine (SPP-BPT): In a cogeneration setup, much like ICE's and GT's, they are characterised by $\beta=0$ and $\eta_{\text {non-CHP,E }}=\eta_{\mathrm{E}}$. The herein simulated plant configuration is made up of a fossil fuel boiler (fed by natural gas), a steam turbine and a deaerator. Simulations have been conducted for turbine final pressures in the range from 5 to 40 bars in order to take into account the effects related to the different quality conditions (temperature, pressure) of the heat required by final users. Main energy parameters $\left(E_{\mathrm{CHP}} / E, F / E\right.$ and $\left.\mathrm{PES}\right)$ have been deduced: such parameters refer to power plant size not smaller than $5 \mathrm{MWe}$ and this numerical investigation has been conducted by varying $H_{\mathrm{CHP}} / E$ ratio, that is varying turbine final pressures in the range from 5 to 40 bar;

- Steam Power Plants with Condensing Turbine (SPP-CT): they are characterised by $\beta>0$ and $\eta_{\text {nonCHP,E }}>\eta_{\mathrm{E}}$. Simulations have been conducted taking into account a plant configuration made of a fossil fuel boiler (fed by natural gas), a steam turbine, a condenser and a deaerator. Pressures are assumed in the range from 5 to 40 bars to include the effects related to the different quality conditions (temperature, pressure) of the heat required by final users. Main energy parameters $\left(E_{\mathrm{CHP}} / E, F / E\right.$ and PES) have been deduced with reference to power plant size not smaller than 5 MWe. This numerical investigation has been conducted by varying $H_{\mathrm{CHP}} / E$ ratio, that is by varying, for each extraction pressure set, the extracted steam flow rate up to the maximum limit, that in turn is achieved for a mass flow rate at the condenser inlet, not less than $20 \%$ the design mass flow rate at the inlet of the turbine;

- Combined Cycle Power Plants (CCPP) with condensing turbine: In a cogeneration setup, they are characterised by $\beta>0$ and $\eta_{\text {nonCHP,E }}>\eta_{\mathrm{E}}$. A plant configuration made up of a gas turbine (similar to the gas turbine LS introduced above), a HRSG with two pressure levels, a steam section with condensing turbine and condenser has been herein taken into account. Simulations have been conducted for extraction pressures in the range from 5 to 40 bar so as to model the effects related to the different quality conditions (temperature, pressure) of the heat required by final users. Main energy parameters $\left(E_{\mathrm{CHP}} / E, F / E\right.$ and $\left.\mathrm{PES}\right)$ have been deduced: such parameters refer to power plant size not smaller than $50 \mathrm{MWe}$. Numerical investigations have been conducted by varying $H_{\mathrm{CHP}} / E$ ratio, that is by varying, for each extraction pressure set, the extracted steam flow rate until to the maximum limit, that, in turn, is achieved for a mass flow rate, at the condenser inlet, not less than $20 \%$ the design mass flow rate at the inlet of the steam turbine.

\section{Performance parameters of chosen technologies}

The above-illustrated characterisation of cogeneration technologies allowed for determination of the following parameters for each technology: $H_{\mathrm{CHP}} / E, F / E, E_{\mathrm{CHP}} / E$, and PES. As concerns the choice of such characteristic parameters, the following considerations must be taken into account:

- A range of values for the most significant energy parameters must be defined for each cogeneration technology, by categorising power plants according to their size (ICE and GT) and quality (temperature level) of the produced heat (SPP-BPT, SPP-CT, and CCPP). Such a subdivision derives from the fact that, for ICE's and GT's, the quality of heat demanded by users does not affect performance considerably, as they are more sensitive to plant size, instead, quality and quantity of heat produced by solutions employing steam cycles (SPP-BPT, SPP-CT, CCPP) affect their performance considerably; 
- Since $H_{\mathrm{CHP}} / E$ ratio varies with cogeneration heat provided to final users, for all technological solutions considered here, a maximum value for $H_{\mathrm{CHP}} / E$ ratio has been chosen (Table 2), this is the case for ICE's and GT's, when providing heat involves exhaust gases to be discharged at temperatures in the range from $90{ }^{\circ} \mathrm{C}$ to $100{ }^{\circ} \mathrm{C}$ and, for ICE's only, and a heat recovery from water/air/oil systems of about $70 \%$. With respect to condensing steam turbine power plants (SPP-CT and CCPP), $H_{\mathrm{CHP}} / E$ value is correlated to the steam extraction from the turbine, it is possible to have the maximum value of $H_{\mathrm{CHP}} / E$ when a maximum value of steam is extracted, it happens when at least $20 \%$ of the mass flow rate entering the turbine passes in the condenser. In SPP-BPT, finally, $H_{\mathrm{CHP}} / E$ value depends only on the quality conditions (steam pressure, temperature) of the heat demanded by the production process;

- $\quad F / E$ and $E_{\mathrm{CHP}} / E$ depend on the chosen $H_{\mathrm{CHP}} / E$ value;

- Concerning PES, for all power plant types, natural gas has been chosen as fuel. To ease into things, adjustments related to weather conditions and to electric grid connection tension values have not been taken into account.

On the basis of such considerations, Table 2 contains the summary of the CHP parameters characterising each cogeneration technology. These parameters are referred to the following power plants sizes: ICE $P_{\mathrm{e}}>100 \mathrm{~kW}$, GT $P_{\mathrm{e}}>1,500 \mathrm{~kW}$, SPP $P_{\mathrm{e}}>3 \mathrm{MW}$ and CCPP $P_{\mathrm{e}}>20 \mathrm{MW}$.

Table 2. Performance parameters of cogeneration technologies

\begin{tabular}{ccccccccc}
\hline & & $\left(H_{\mathrm{CHP}} / E\right)_{\max }$ & $F / E$ & $F_{\mathrm{CHP}} / E$ & $E_{\mathrm{CHP}} / E$ & PES [\%] & $\begin{array}{c}C_{\mathrm{pp}} \\
{[\mathrm{EUR} / \mathrm{kW}]}\end{array}$ & $F_{\mathrm{O \& M}}[\%]$ \\
\hline \multirow{2}{*}{ ICE } & Large size & 0.87 & 2.2 & 2.2 & 1.0 & 23 & 650 & 8 \\
& Small size & 1.1 & 2.5 & 2.5 & 1.0 & 20 & 1,200 & 8 \\
\hline \multirow{2}{*}{$\mathrm{GT}$} & Large size & 1.5 & 2.8 & 2.8 & 1.0 & 22 & 800 & 6 \\
& Small size & 1.9 & 3.4 & 3.4 & 1.0 & 15 & 1,300 & 6 \\
\hline \multirow{2}{*}{$\mathrm{SPP}-\mathrm{BPT}$} & LT heat & 3.8 & 5.4 & 5.4 & 1.0 & 12 & 1,600 & 4 \\
& HT heat & 7.1 & 9.0 & 9.0 & 1.0 & 8 & 1,600 & 4 \\
\hline \multirow{2}{*}{$\mathrm{SPP}-\mathrm{CT}$} & LT heat & 2.5 & 4.6 & 4.2 & 0.86 & 5 & 1,800 & 4 \\
& HT heat & 3.4 & 5.7 & 5.2 & 0.84 & 2 & 1,800 & 4 \\
\hline \multirow{2}{*}{$\mathrm{CCPP}$} & LT heat & 0.60 & 2.2 & 1.7 & 0.78 & 20 & 1,000 & 4 \\
& HT heat & 0.69 & 2.3 & 1.8 & 0.77 & 18 & 1,000 & 4 \\
\hline
\end{tabular}

In addition to these input values, the here-proposed method for power plant sizing requires a set of economic-environmental parameters to determine indicators such as Pay Back Period (PBP), Net Present Value (NPV) to total investment (I) ratio (NPV/I) and $\mathrm{CO}_{2}$ emissions avoided $\left(\mathrm{CO}_{2, \mathrm{a}}\right)$ in comparison to separate electricity and heat productions. Some of these input parameters are indicated in Table 2 and are referred, specifically, to costs. Given the difficulty in defining specific cost of a power plant $\left(C_{\mathrm{pp}}\right)$, in this paper such parameter has been derived from the specific cost per installed $\mathrm{kW}$ for the particular cogeneration technology, including a Balance of Plant (BOP) cost. As for operation and maintenance costs $\left(C_{\mathrm{O} \& \mathrm{M}}\right)$, they have been deduced as a percentage $\left(F_{\mathrm{O} \& \mathrm{M}}\right)$ of the power plant specific cost. All costs-related estimations are based on information available in the literature for the European [42, 43] and the US [44, 45] market, including also the particular Italian context as well as confidential information. The interest rate of invested capital has been assumed in a range 6-10\%.

Concerning environmental performance, the specific $\mathrm{CO}_{2}$ emission factor value has been assumed in accordance with the fuel type adopted (e.g., $55 \operatorname{ton}_{\mathrm{CO}_{2}} / \mathrm{TJ}$ for natural gas). 
Finally, in order to carry out economic evaluations, assumptions need to be made with regard to fuel and electricity costs. Such costs depend mainly on the size of industrial users, taxes, excise duties and so on. These parameters have been adopted, with reference to the Italian context regarding energy pricing and size of companies, as follows:

- Cost of electric energy drawn from the grid, 115-200 EUR/MWh [46];

- Cost of natural gas for cogeneration purposes: 28-60 EUR/MWh [46];

- Additional excise duty for natural gas when not utilised for cogeneration purposes: 5 EUR/MWh.

\section{SELECTION AND SIZING METHOD FOR COGENERATION UNITS INTEGRATED IN INDUSTRIAL SECTORS}

The selection and sizing method for CHP units in industrial sectors is described below, along with results of the conducted evaluation.

\section{Input data of the method}

The selection and sizing method for CHP units to be installed in industrial sectors is based on results related to the investigations conducted in the previous sections. In particular, the characterisation of sectors, carried out in the previous paragraph, has enabled to calculate the specific electric and thermal consumption of the most important production processes. In this stage, in order to design the specific power plant, additional parameters are needed:

- Production: This information allows for the quantification of the energy demand (electricity and heat) of the analysed process, since the sectors considered in the study are numerous and small, medium and large companies can be found within the individual sectors, numerical investigations will be parameterised on the basis of production (i.e., small, medium and large production: 1,000, 50,000 and 400,000 ton/year respectively) [47, 48];

- Operating hours: An annual operating period equal to 7,000 hours has been assumed $[47,48]$;

- Characteristics of process heat: Steam or gases as thermal vector and medium-low temperature level.

\section{Sizing method for cogeneration units}

The ratio $P_{\mathrm{t}} / P_{\mathrm{e}}$ of the process - thermal to electric power ratio, $\left(P_{\mathrm{t}} / P_{\mathrm{e}}\right)_{\text {process }}-$ can be calculated according to input data of the process (specific thermal and electric consumption, production and operating hours) as displayed in Figure 1a.

Next step is the application of the elaborated sizing criterion, which is founded on two fundamental hypotheses:

- Heat made available by the cogeneration unit has to be used at its most, in order to have a full harnessing of the maximum $H_{\mathrm{CHP}} / E$ ratio of the cogenerator, allowing for the achievement of the best HEC performances;

- Electricity has not to be exported to the national grid, therefore, the plant is designed according to an electric power equal at most to that required by the process.

Then the $\left(P_{\mathrm{t}} / P_{\mathrm{e}}\right)_{\text {process }}$ ratio has to be compared to $\left(P_{\mathrm{t}} / P_{\mathrm{e}}\right)_{\text {technology }}$ ratio of the specific cogeneration technology and, if the process ratio prevails:

$$
\left(\frac{P_{\mathrm{t}}}{P_{\mathrm{e}}}\right)_{\text {process }}>\left(\frac{P_{\mathrm{t}}}{P_{\mathrm{e}}}\right)_{\text {technology }}
$$

it means that the chosen cogeneration technology will be capable of satisfying the electric demand of the process, but not the thermal demand, therefore, the cogeneration unit will 
be designed according to electric power of the process and auxiliary boilers will satisfy the additional thermal demand of the process.

However, if the result of the comparison is the following:

$$
\left(\frac{\mathrm{P}_{t}}{\mathrm{P}_{e}}\right)_{\text {process }}<\left(\frac{\mathrm{P}_{t}}{\mathrm{P}_{e}}\right)_{\text {technology }}
$$

it means that the chosen cogeneration technology will be capable of satisfying completely the thermal demand of the process, but not the electric demand, therefore, the cogeneration unit will be designed according to thermal power of the process while additional electricity, to satisfy electric demand of the process, will be drawn from the national grid.

The implementation of the above-described criterion, as visible also in Figure 1b, allows the design of both the cogeneration unit [electric power, useful (cogeneration) thermal power and fuel thermal power] and auxiliary boilers (that is, the calculation of thermal power correlated to the production of heat in auxiliary systems) and enables the calculation of the electric power drawn from the grid. In order to quantify fuel thermal powers, the Italian reference efficiency values have been adopted (which are used in the calculation of a national HEC parameter, they are equal to $0.82 / 0.9$ and represent average conventional efficiencies of typical Italian heat systems in the case of direct use of exhaust gases and in the case of steam/hot water production, respectively).
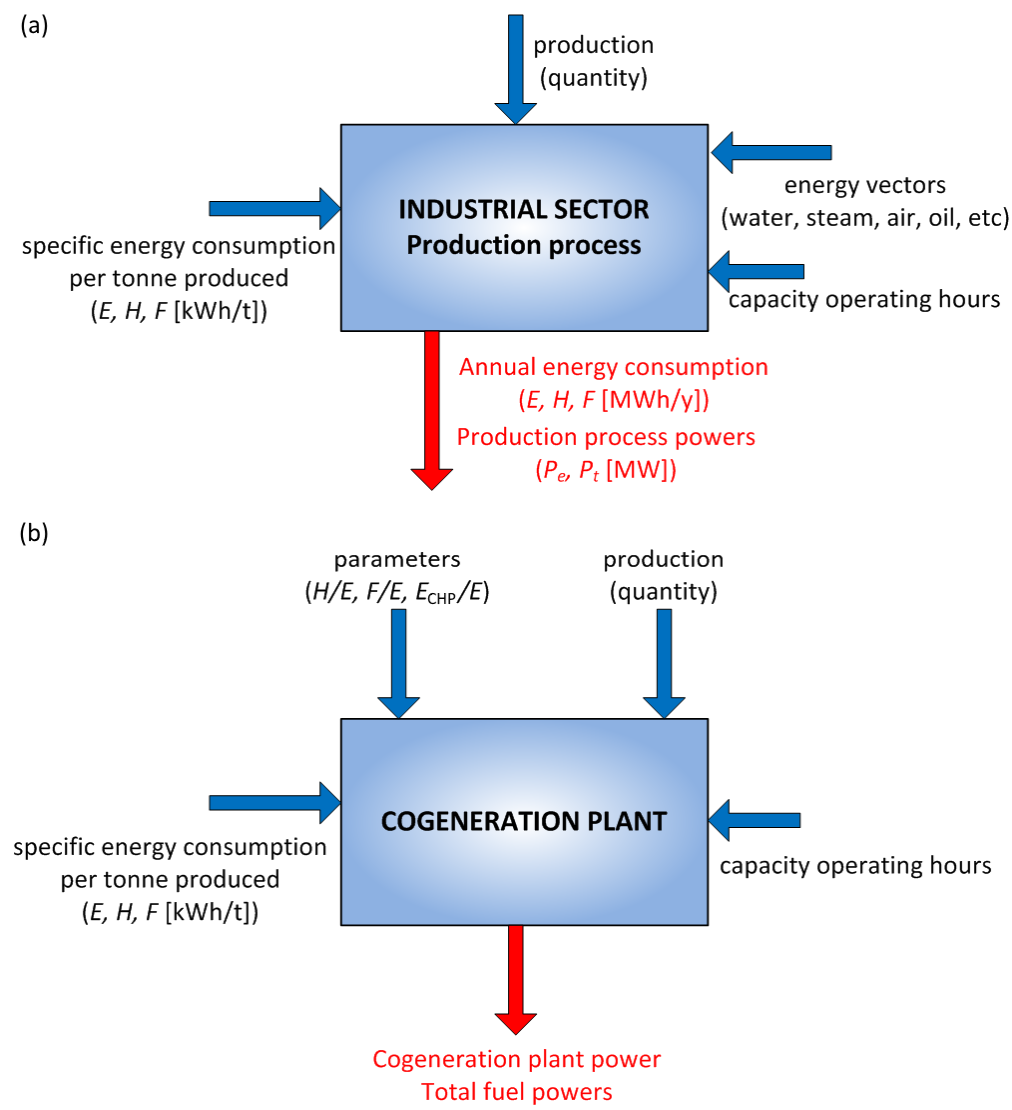

Figure 1. Sizing method for cogeneration units integrated in industrial sectors

Once the sizing of cogeneration unit is finalized, CHP energetic performances, in terms of PES, can be assessed for the chosen technology.

Upon completion of the energy design of the cogeneration unit, the following step consists in the evaluation of economic-environmental parameters of the power plant, both 
in the absence and in the presence of the cogeneration unit. By means of the estimation of the annual cash flow, economic saving, PBP and the ratio of NPV to the investment (NPV/I) can be quantified.

Avoided $\mathrm{CO}_{2}$ emissions can also be assessed evaluating both fuel emission factor and fuel thermal energies.

\section{RESULTS}

The method described in the previous paragraphs has been applied to the 10 identified industrial cases, taking also into consideration the size of the production processes.

\section{Analysis of results by industrial process}

Table 3 displays main energy, economic and environmental results. This table is composed of 10 horizontal blocks, representing industrial process here analysed, each horizontal block is composed of three rows, each row represents a production (that is, size of the production process).

Table 3. Energy, economic and environmental results

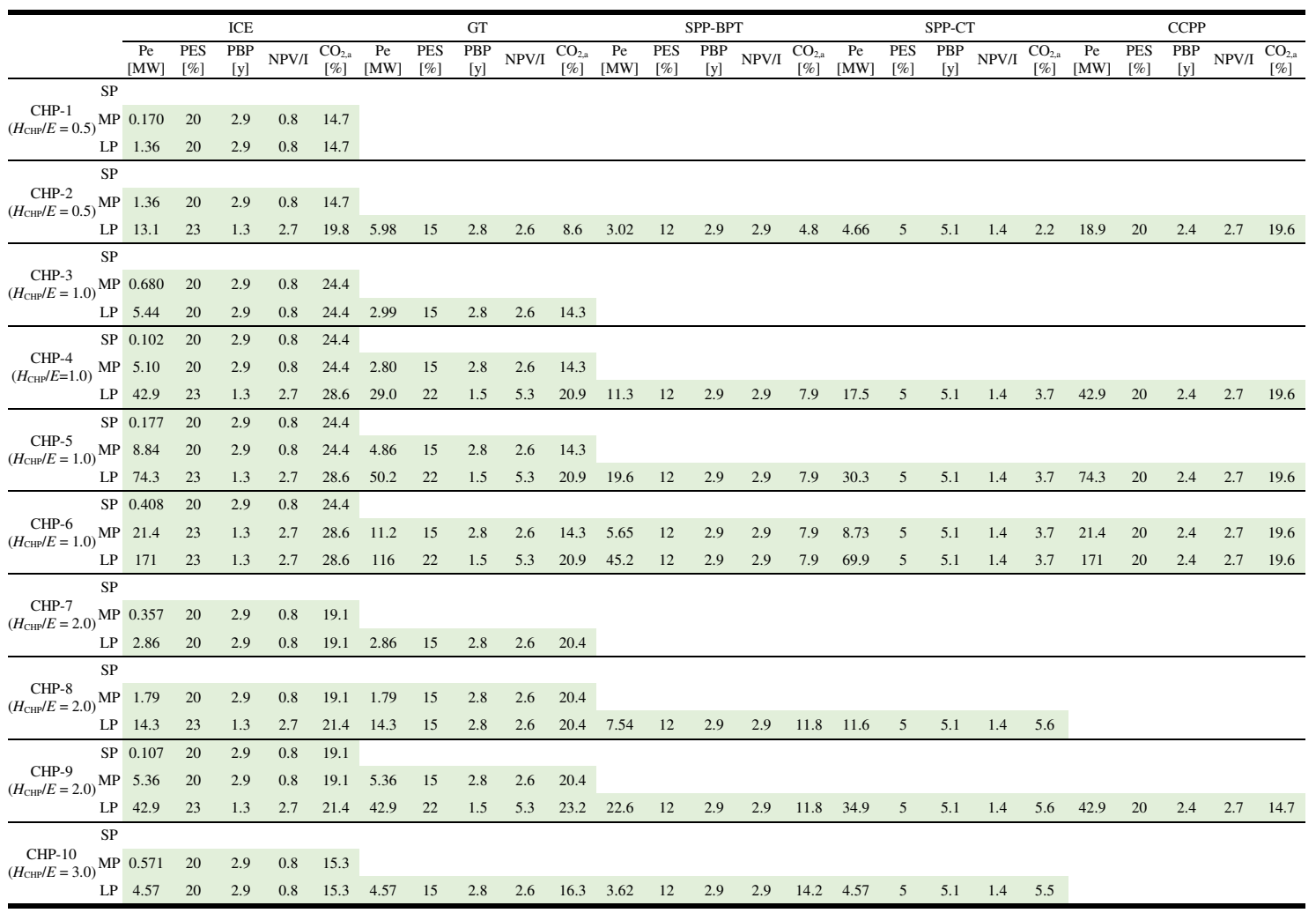

This table is then composed of five vertical blocks, representing cogeneration power plants herein analysed, each vertical block is composed of five column, each column represents respectively electric power and four cogeneration performance parameters.

Some cells of this table are green and they contain numbers, while other ones are white and they do not contain numbers. In this last case, it means that no integration is possible between industrial process and power plant for technological reasons.

In this paragraph, results can be analysed through horizontal blocks:

- Low-heat-requirement production sectors $\left(H_{\mathrm{CHP}} / E=0.5\right)$;

O CHP-1 process: CHP-1 process cannot be coupled with any cogeneration technology if it is characterised by small production [lower than 1,000 ton/year)]. Indeed, in this case, maximum cogeneration plant size would be lower than $10 \mathrm{kWe}$. 
In the case of industrial processes with medium production (about 50,000 ton/year), cogeneration plant size is so small that only ICE's are a suitable solution, in fact, they are the only technological solutions installable when the cogeneration plant sizes are about $150 \mathrm{kWe}$. In this case, performance parameters show a PES value of about $20 \%$, a PBP of almost 3 years and an economic profitability equal to 0.8 , the reduction in $\mathrm{CO}_{2}$ emissions with respect to separate production is about $15 \%$. Even in the case of industrial processes with large production (about 400,000 ton/year), cogeneration plant size (about 1.4 MWe) is so small that only ICE's are a suitable solution. In this case, performance parameters are exactly equal to the previous ones.

- CHP-2 process: CHP-2 process cannot be coupled with any cogeneration technology if characterised by small production (lower than 1,000 ton/year). Indeed, in this case, maximum cogeneration plant size would be lower than $30 \mathrm{kWe}$.

In the case of industrial processes with medium production (about 50,000 ton/year), cogeneration plant size is so small (1.4 MW) that only ICE's are a suitable solution. In this case, the performance parameters show a PES value of about $20 \%$, a PBP of almost 3 years and an economic profitability equal to 0.8 , the reduction in $\mathrm{CO}_{2}$ emissions with respect to separate production is about $15 \%$.

In the case of industrial processes with large production (about 400,000 ton/year), cogeneration plant sizes are so high that all cogeneration technologies analysed in this paper are possible suitable solutions. ICE's and GT's are characterised by sizes in the range 6-13 MWe, steam power plants (coupled with processes requiring heat at lower temperature) are characterised by electric power values between 3-5 MWe, CCPP's (coupled with processes requiring heat at lower temperature) are characterised by electric power values of about 20 MWe. HEC performance parameters exhibit a PES value lower than the threshold value only for SPP-CT and higher (12-23\%) for all the other technologies. Economic performance parameters show a PBP of barely more than 1 year for ICE's (LS) and an interesting economic profitability for ICE's and combined cycles (2.7), even though SPP-BPT have the greatest economic profitability (2.9). Environmental performance parameters show a substantial reduction in $\mathrm{CO}_{2}$ emissions for ICE's and combined cycles. It is clear that SPP-CT are a solution to be discarded (PES lower than the threshold value), ICE seems the preferable technological solution, but also CCPP's are able to attain good performance, albeit with quite small power plant sizes.

- Medium-heat-requirement production processes $\left(H_{\mathrm{CHP}} / E=1.0\right)$;

○ CHP-3 process: CHP-3 process cannot be coupled with any cogeneration technology if characterised by small production (lower than 1,000 ton/year). Indeed, in this case, maximum cogeneration plant size would be lower than a few $\mathrm{kWe}$.

In the case of industrial processes with medium production (about 50,000 ton/year), cogeneration plant size is so small (about $700 \mathrm{kWe}$ ) that only ICE's are a suitable solution. In this case, the performance parameters show a PES value of about $20 \%$, a PBP of almost 3 years and an economic profitability equal to 0.8 , the reduction in $\mathrm{CO}_{2}$ emissions with respect to separate production is higher than $24 \%$.

In the case of industrial processes with large production (about 400,000 ton/year), cogeneration plant size is such that only ICE's and GT's are suitable solutions with sizes of 3-6 MWe. HEC performance parameters exhibit a PES value of about $20 \%$ for ICE's and $15 \%$ for GT's. Economic performance 
parameters show a PBP of almost 3 years for both technologies and an interesting economic profitability for GT's: it is equal to $2.6 \mathrm{vs}$. a value of about 0.8 for ICE's. Environmental performance parameters show a substantial reduction in $\mathrm{CO}_{2}$ emissions for ICE's (more than 24\%). The two technological solutions are nearly equivalent: if, from an economic point of view, GT's is preferable (higher NPV/I), from an energy-environmental point of view, ICE displays a higher PES value and ensures a more significant environmental impact reduction.

- CHP-4 process: CHP-4 process can be coupled only with ICE's, if characterised by small production (lower than 1,000 ton/year), installable power values are about $100 \mathrm{kWe}$. In this case, performance parameters exhibit a PES value of about $20 \%$, a PBP of almost 3 years and an economic profitability equal to 0.8 , the reduction in $\mathrm{CO}_{2}$ emissions is higher than $24 \%$.

In the case of industrial processes with medium production (about 50,000 ton/year), cogeneration plant size is such that only ICE's and GT's are suitable solutions with sizes of 3-5 MWe. HEC performance parameters exhibit a PES value of about $20 \%$ for ICE's and $15 \%$ for GT's. Economic performance parameters show a PBP of almost 3 years for both technologies and an interesting economic profitability for GT's, equal to $2.6 \mathrm{vs}$. a value of about 0.8 for ICE's. Environmental performance parameters reveal a higher reduction in $\mathrm{CO}_{2}$ emissions for ICE's. The two technological solutions are nearly equivalent: if, from an economic point of view, GT's is preferable (higher NPV/I), from an energy-environmental point of view, ICE displays a higher PES value and ensures a more significant reduction in environmental impact.

In the case of industrial processes with large production (about 400,000 ton/year), cogeneration plant size is so high that all cogeneration technologies here analysed are a possible suitable solution: ICE's and combined cycles (coupled with processes requiring heat at lower temperature) are characterised by sizes of about $40 \mathrm{MWe}$, GT's of about $30 \mathrm{MWe}$ and steam power plants (coupled with processes requiring heat at lower temperature) of 11-17 MWe. HEC performance parameters exhibit a PES value lower than the threshold value only for SPP-CT and higher (12-23\%) for all the other technologies. Economic performance parameters show a minimum PBP value (about 1.3 years) for ICE's (LS), and an extremely interesting economic profitability for GT's (NPV/I equal to 5.3). Environmental performance parameters reveal a substantial reduction in $\mathrm{CO}_{2}$ emissions of more than $28 \%$ for ICE's. It is clear that SPP-CT are a solution to be discarded (PES lower than the threshold value), the preferable technological solution is the gas turbine, which grants also good environmental performances (better than those of combined cycles, but worse than those of ICE's).

- CHP-5 process: CHP-5 process can be coupled only with ICE's if it is characterised by small production (lower than 1,000 ton/year), installable power values are about $180 \mathrm{kWe}$. In this case, performance parameters exhibit a PES value of about $20 \%$, a PBP of almost 3 years and an economic profitability equal to 0.8 , the reduction in $\mathrm{CO}_{2}$ emissions is higher than $24 \%$.

In the case of industrial processes with medium production (about 50,000 ton/year), cogeneration plant size is such that only ICE's and GT's are suitable solutions with sizes of 5-9 MWe. HEC performance parameters exhibit a PES value of about $20 \%$ for ICE's and $15 \%$ for GT's. Economic performance parameters exhibit a PBP of almost 3 years for both technologies and an interesting economic profitability for GT's: equal to $2.6 \mathrm{vs}$. a value of about 0.8 for ICE's. Environmental performance parameters show a higher reduction in 
$\mathrm{CO}_{2}$ emissions for ICE's. The two technological solutions are nearly equivalent: if, from an economics point of view, GT's is preferable (higher NPV/I), from an energy-environmental point of view, ICE displays a higher PES value and ensures a more significant reduction in environmental impact.

In the case of industrial processes with large production (about 400,000 ton/year), cogeneration plant sizes are so high that all cogeneration technologies here analysed are possible suitable solutions: ICE's and combined cycles (coupled with processes requiring heat at lower temperature) are characterised by sizes of about 75 MWe, GT's of about 50 MWe and steam power plants (coupled with processes requiring heat at lower temperature) of 20-30 MWe. HEC performance parameters exhibit a PES value lower than the threshold value only for SPP-CT and higher (12-23\%) for all the other technologies. Economic performance parameters show a minimum PBP value (about 1.3 years) for ICE's (LS) and an extremely interesting economic profitability for GT's (NPV/I equal to 5.3). Environmental performance parameters reveal a substantial reduction in $\mathrm{CO}_{2}$ emissions, more than $28 \%$, for ICE's. It is clear that SPP-CT are a solution to be discarded (PES lower than the threshold value), the preferable technological solution is the gas turbine, which grants also good environmental performances (better than those of combined cycles, but worse than those of ICE's).

- CHP-6 process: CHP-6 process can be coupled only with ICE's if it is characterised by small production (1,000 ton/year), installable electric power values are about $400 \mathrm{kWe}$. In this case, performance parameters exhibit a PES value of about $20 \%$, a PBP of almost 3 years and an economic profitability equal to 0.8 , the reduction in $\mathrm{CO}_{2}$ emissions with respect to separate production is higher than $24 \%$.

In the case of industrial processes with medium production (50,000 ton/year), cogeneration plant size is such that all cogeneration technologies analysed in this paper are possible suitable solutions: ICE's and combined cycles (coupled with processes requiring heat at lower temperature) are characterised by electric power size of about $20 \mathrm{MWe}$, GT's of about $5 \mathrm{MWe}$ and steam power plants (coupled with processes requiring heat at lower temperature) in the range 5-9 MWe. HEC performance parameters exhibit a PES value lower than the threshold value only for SPP-CT and higher (12-23\%) for all the other technologies. Economic performance parameters show a PBP of barely more than 1 year for ICE's (LS) and an interesting economic profitability for SPP-BPT (2.9). Environmental performance parameters reveal a substantial reduction in $\mathrm{CO}_{2}$ emissions, more than $28 \%$, for ICE's. It is clear that SPP-CT are a solution to be discarded (PES lower than the threshold value), ICE seems the preferable technological solution, but also CCPP's can attain good performance, even though the power plant sizes are quite small.

Also in the case of industrial processes with large production (400,000 ton/year), cogeneration plant size is such that all cogeneration technologies analysed in this paper are possible suitable solutions: ICE's (in a cogeneration plant configuration with more engines in parallel) and combined cycles (coupled with processes requiring heat at lower temperature) are characterised by electric power sizes of about $170 \mathrm{MWe}$, GT's of about $115 \mathrm{MWe}$ and steam power plants (coupled with processes requiring heat at lower temperature) in the range 45-70 MWe. HEC performance parameters exhibit a PES value lower than the threshold value only for SPP-CT and higher (12-23\%) for all the other technologies. Economic performance parameters show a PBP of barely more than 1 year for ICE's (LS) and an interesting economic profitability for GT's 
(5.3). Environmental performance parameters reveal a substantial reduction in $\mathrm{CO}_{2}$ emissions, more than $28 \%$, for ICE's. It is clear that SPP-CT are a solution to be discarded (PES lower than the threshold value), the gas turbine seems the preferable technological solution, while ICE, despite providing similar performances, does not seem particularly appropriate since the resulting power plant size requires installation of more engines in parallel, CCPP's attain good performance, although slightly worse than GT's.

- High-heat-requirement production sectors $\left(H_{\mathrm{CHP}} / E=2.0\right)$;

○ CHP-7 process: CHP-7 process cannot be coupled with any cogeneration technology if it is characterised by small production (1,000 ton/year). Indeed, in this case, maximum cogeneration plant size would be lower than a few kWe.

In the case of industrial processes with medium production (50,000 ton/year), cogeneration plant size is so small that only ICE's are a suitable solution. In this case, the performance parameters show a PES value of about $20 \%$, a PBP of almost 3 years and an economic profitability equal to 0.8 , the reduction in $\mathrm{CO}_{2}$ emissions is almost $20 \%$.

In the case of industrial processes with large production $(400,000$ ton/year), cogeneration plant size is such that only ICE's and GT's are suitable solutions with electric power sizes of about 3 MWe. HEC performance parameters exhibit a PES value of about $20 \%$ for ICE's and $15 \%$ for GT's. Economic performance parameters show a PBP of almost 3 years for both technologies and an interesting economic profitability for GT's: equal to $2.6 \mathrm{vs}$. a value of about 0.8 for ICE's. Environmental performance parameters reveal a similar reduction in $\mathrm{CO}_{2}$ emissions (about 20\%). The two technological solutions are nearly equivalent: if, from an economic point of view, GT's seem to be preferable (higher NPV/I), from an energy-related point of view, ICE's display the highest PES value.

- CHP-8 process: CHP-8 process cannot be coupled with any cogeneration technology if it is characterised by small production (1,000 ton/year). Indeed, in this case, maximum cogeneration plant size would be lower than $40 \mathrm{kWe}$.

In the case of industrial processes with medium production (50,000 ton/year), cogeneration plant size is such that only ICE's and GT's are suitable solutions with electric power sizes of about $2 \mathrm{MWe}$. HEC performance parameters exhibit a PES value of about $20 \%$ for ICE's and $15 \%$ for GT's. Economic performance parameters show a PBP of almost 3 years for both technologies and an interesting economic profitability for GT's: equal to 2.6 vs. a value of about 0.8 for ICE's. Environmental performance parameters reveal a similar reduction in $\mathrm{CO}_{2}$ emissions (about 20\%). The two technological solutions are nearly equivalent: if, from an economic point of view, GT's seem to be preferable (higher NPV/I), from an energy-related point of view, ICE's display the highest PES value.

In the case of industrial processes with large production (400,000 ton/year), cogeneration plant size is such that all cogeneration technologies analysed in this paper are possible suitable solutions, except CCPP's: ICE's and GT's are characterised by electric power sizes of about $15 \mathrm{MWe}$ and steam power plants (coupled with processes requiring heat at lower temperature) in the range 7.5-11.5 MWe. HEC performance parameters exhibit a PES value lower than the threshold value only for SPP-CT and higher (12-23\%) for all the other technologies. Economic performance parameters show a PBP of barely more than 1 year for ICE's (LS) and an interesting economic profitability for SPP-BPT (2.9). Environmental performance parameters reveal a substantial reduction in $\mathrm{CO}_{2}$ emissions, about 20\%, for ICE's and GT's. It is clear that SPP-CT are a 
solution to be discarded (PES lower than the threshold value), ICE seems the preferable technological solution.

- CHP-9 process: CHP-9 process can be coupled only with ICE's if characterised by small production (1,000 ton/year), installable power values are about $100 \mathrm{kWe}$. In this case, performance parameters show a PES value of about $20 \%$, a PBP of almost 3 years and an economic profitability equal to 0.8 , the reduction in $\mathrm{CO}_{2}$ emissions is almost $20 \%$.

In the case of industrial processes medium production (50,000 ton/year), cogeneration plant size is such that only ICE's and GT's are suitable solutions with electric power sizes of more than 5 MWe. HEC performance parameters exhibit a PES value of about $20 \%$ for ICE's and $15 \%$ for GT's. Economic performance parameters show a PBP of almost 3 years for both technologies and an interesting economic profitability for GT's: equal to $2.6 \mathrm{vs}$. a value of about 0.8 for ICE's. Environmental performance parameters reveal a similar reduction in $\mathrm{CO}_{2}$ emissions (about 20\%). The two technological solutions are nearly equivalent: if, from an economics point of view, GT's seem to be preferable (higher NPV/I), from an energy-related point of view, ICE's display the highest PES value.

In the case of industrial processes with large production (about 400,000 ton/year), cogeneration plant size is such that all cogeneration technologies analysed in this paper are possible suitable solutions: ICE's, GT's and CCPP's (coupled with processes requiring heat at lower temperature) are characterised by electric power sizes of about $40 \mathrm{MWe}$ and steam power plants (coupled with processes requiring heat at lower temperature) in the range 22-35 MWe. HEC performance parameters exhibit a PES value lower than the threshold value only for SPP-CT and higher (12-23\%) for all the other technologies. Economic performance parameters show a PBP of barely more than 1 year for ICE's (LS) and an interesting economic profitability for gas turbines (5.3). Environmental performance parameters reveal a substantial reduction in $\mathrm{CO}_{2}$ emissions, more than $23 \%$, for GT's. It is clear that SPP-CT are a solution to be discarded (PES lower than the threshold value), GT's and ICE's seem the preferable technological solution, CCPP's attain good performance, although slightly worse than GT's.

- Very high-heat-requirement production sectors $\left(H_{\mathrm{CHP}} / E=3.0\right)$;

- CHP-10 process: CHP-10 process cannot be coupled with any cogeneration technology if characterised by small production (1,000 ton/year). Indeed, in this case, cogeneration plant maximum size would be lower than a few kWe.

In the case of industrial processes with medium production (50,000 ton/year), cogeneration plant size is so small that only ICE's are a suitable solution with electric power sizes of about $600 \mathrm{kWe}$. In this case, the performance parameters show a PES value of about $20 \%$, a PBP of almost 3 years and an economic profitability equal to 0.8 , the reduction in $\mathrm{CO}_{2}$ emissions is about $15 \%$.

In the case of industrial processes with large production $(400,000$ ton/year), cogeneration plant size is such that all cogeneration technologies analysed in this paper are possible suitable solutions, except CCPP's: ICE's and GT's are characterised by electric power sizes of about $5 \mathrm{MWe}$ and steam power plants (coupled with processes requiring heat at lower temperature) in the range 3.6-4.6 MWe. HEC performance parameters exhibit a PES value lower than the threshold value only for SPP-CT and higher (12-20\%) for all the other technologies. Economic performance parameters show a PBP of about 3 years for all the technologies with the exception of SPP-CT (for which it is more than 5 years) and an interesting economic profitability for GT's and SPP-BPT (2.6 and 2.9 , respectively). Environmental performance parameters reveal a substantial 
reduction in $\mathrm{CO}_{2}$ emissions, more than $15 \%$, for ICE's and GT's. It is clear that SPP-CT are a solution to be discarded (PES lower than the threshold value), GT's seem to be the preferable technological solution, but also ICE's and SPP-BPT provide interesting performances.

All the above-discussed results are also displayed in Figures 2-5, in which it is possible to compare different technological solutions for the analysed industrial sectors. Obviously, with respect to Table 3, energetic, economic and environmental performance parameters are not graphically depicted for those sectors in which none or only one power plant solution is viable. The following paragraphs summarise the main conclusions for each class of production processes.

Production processes with low heat requirement $\left(H_{\mathrm{CHP}} / E=0.5\right)$, that is CHP-1 and CHP-2, cannot be integrated with any cogeneration power plants when production are low (lower than 1,000 ton/year). For the same industrial processes with medium and large production, cogeneration plants based on ICE represent a good solution, CCPP's appear interesting only if industrial processes (CHP-2) are characterised by specific thermal consumption of about $200 \mathrm{kWh} /$ ton and by production higher than 400,000 ton/year.

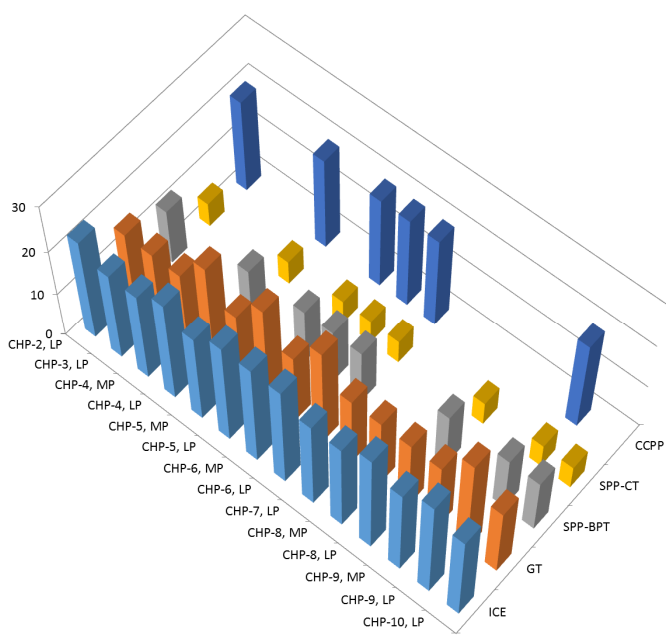

Figure 2. Energy Performance (PES)

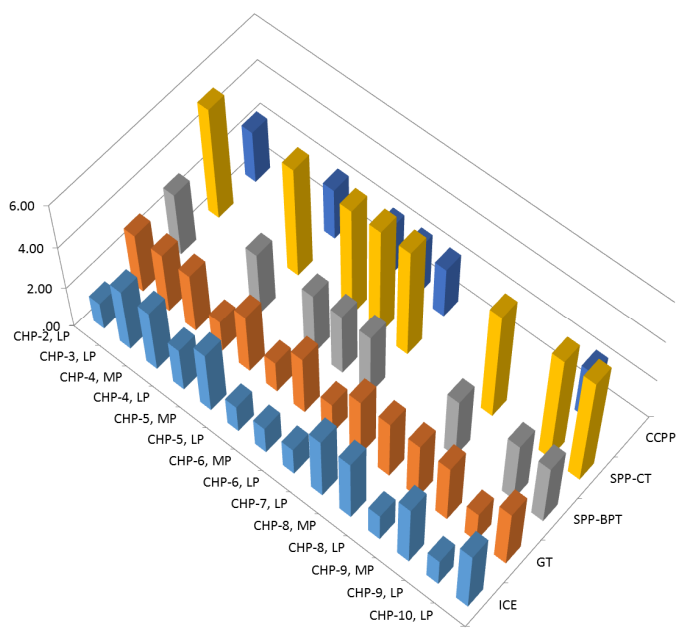

Figure 4. Economic Performance (PBP) [years]

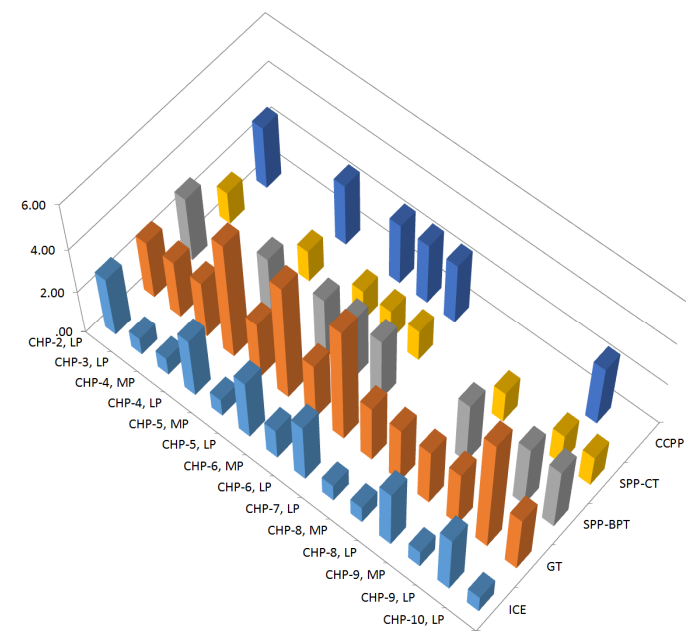

Figure 3. Economic Performance (NPV/I)

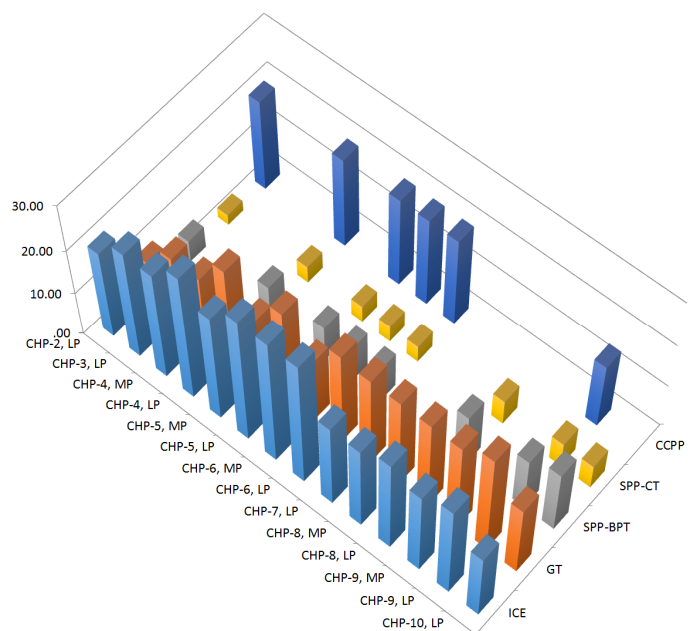

Figure 5. Environmental Performance $\left(\mathrm{CO}_{2, \mathrm{a}}\right)[\%]$

Production processes with medium heat requirement $\left(H_{\mathrm{CHP}} / E=1.0\right)$, can be integrated with gas turbines and/or ICE's when industrial processes are characterised by specific thermal consumption in the range 100-1,300 $\mathrm{kWh} /$ ton and by low/medium 
production (1,000-50,000 ton/year). All the analysed cogeneration technologies are suitable for industrial processes characterised by specific thermal consumption in the range $750-3,000 \mathrm{kWh} /$ ton and by large production (400,000 ton/year): gas turbines turn out to be the best solution, while ICE's, despite providing similar performances, do not seem particularly appropriate since the resulting plant size would require multiple engines instead of a single large unit (the resulting size is too big for a single unit), CCPP's attain good performance, although slightly worse than GT's.

Production processes with high heat requirement $\left(H_{\mathrm{CHP}} / E=2.0\right)$, can be integrated with cogeneration plants based on GT's and/or ICE's when they characterised by small specific thermal consumption $(100 \mathrm{kWh} / \mathrm{ton})$ and by medium/large production (50,000-400,000 ton/year) or by higher specific thermal consumption (500-1,500 kWh/ton) and by small/medium production (1,000-50,000 ton/year). All the analysed cogeneration technologies are suitable for industrial processes characterised by specific thermal consumption in the range $500-1,500 \mathrm{kWh} / \mathrm{ton}$ and by large production (400,000 ton/year): GT's and/or ICE's (in a configuration with multiple engines instead of a single large unit) prove to be the best solutions, CCPP's attain good performance only for production processes with high heat requirement (specific thermal consumption of $1,500 \mathrm{kWh} / \mathrm{ton}$ ), although slightly worse than GT's.

\section{Analysis of obtained results by cogeneration technologies}

In this paragraph, results have been analysed by using vertical blocks revealing important observations. In fact, with respect to the individual technologies, the following considerations can be drawn:

- Almost all the analysed production processes can be coupled with ICE-based cogeneration plants, when this cogeneration plant type is not feasible, all the other ones are also not feasible, for high cogeneration plant sizes (higher than $50 \mathrm{MW}$ ), when matched to production processes with medium/high thermal demand and with large production, other cogeneration solutions could become more competitive (gas turbines or combines cycle power plants) even if they exhibit worse economic and environmental performances, as ICE's must adopt a configuration with multiple engines;

- GT's can be proposed in various applications, although to a lesser extent than those of ICE's, and, in some cases, especially for plant sizes larger than $50 \mathrm{MW}$, they can provide economic performance parameters (PBP and NPV/I) higher than those attained by ICE's;

- Technologies based on SPP-CT and backpressure turbine are feasible only in the case of industrial processes characterised by large production, SPP-CT never reach the threshold value for PES and are characterised by lower economic performance parameters than SPP-BPT, SPP-BPT appear to be competitive for industrial processes showing a very high heat demand and significant production;

- CCPP's can be proposed only for those industrial processes characterised by large production and they generally exhibit economic performance parameters (PBP and NPV/I) higher than those provided by SPP-BPT, but lower than those of GT's and ICE's.

Concerning the individual parameters analysed, the following considerations can be drawn:

- PES: If excluding SPP-CT e, all analysed technologies display a PES value $>10 \%$ in the different fields of application. Of course, in the selection of the most appropriate technological solution for the application, it is important to take into account incentives granted for the operation in HEC regime. In Italy, such incentives are provided on the basis of a parameter comparable to PES (however, adopting 
reference efficiencies typical of the Italian context), therefore, a cogeneration plant solution displaying the maximum value for PES would be preferable. Among all the considered applications, ICE's feature the highest PES values, CCPP's are characterised by good values for PES, in some applications even higher than those of GT's, SPP-CT never allow for an operation in HEC regime (obviously considering the natural gas as fuel);

- PBP: In several applications, ICE's show the lowest values for PBP, immediately followed by GT's, CCPP's are characterised by good values for PBP, in certain applications even better than GT's, steam power plants are characterised by higher values for PBP, especially in the condensing turbine configuration;

- NPV/I: GT's are the top power plants only in a few sectors, in all of the other applications, all technologies appears to be nearly equivalent, with the exception of SPP-CT, small-sized ICE's are characterised by quite low values for NPV/I parameter;

- Avoided $\mathrm{CO}_{2}$ emissions: ICE's are the most competitive power plants in almost all the analysed sectors, also GT's and combined cycles involve substantial reductions in $\mathrm{CO}_{2}$ emissions with respect to separate production, steam power plants, especially with condensing turbine, display the weakest environmental performances.

\section{Definition and evaluation of the total key performance indicator}

With respect to the individual analysed processes, in order to identify the technologies most suited to the specific application, TKPI has been defined for the herein-proposed cogeneration solutions, it is expressed through the relation indicated below:

$$
\begin{gathered}
\mathrm{TKPI}_{\mathrm{i}}=\mathrm{KPI}_{\mathrm{PES}, \mathrm{i}}+\mathrm{KPI}_{\mathrm{PBP}, \mathrm{i}}+\mathrm{KPI}_{\mathrm{NPV} / \mathrm{I}, \mathrm{i}}+\mathrm{KPI}_{\mathrm{CO}_{2, \mathrm{a}}, \mathrm{i}} \\
\mathrm{TKPI}_{\mathrm{i}}=\frac{\mathrm{PES}_{\mathrm{i}}}{\mathrm{PES}_{\max }}+\frac{\mathrm{PBP}_{\min }}{\mathrm{PBP}_{\mathrm{i}}}+\frac{(\mathrm{NPV} / \mathrm{I})_{\mathrm{i}}}{(\mathrm{NPV} / \mathrm{I})_{\max }}+\frac{\mathrm{CO}_{2, \mathrm{a}, \mathrm{i}}}{\mathrm{CO}_{2, \mathrm{a}, \max }}
\end{gathered}
$$

and it can be calculated for each of the identified technological solution. It's value cannot exceed 4 and the maximum values (minimum in the case of PBP), indicated in the formula above, refer to the maximum (minimum) value of each parameter, as can be inferred from Table 3. The total key performance indicators are shown in Figure 6 and the following considerations can be drawn according to processes requirements:

- Production processes with low heat requirement $\left(H_{\mathrm{CHP}} / E=0.5\right)$ and small production, cannot be matched with any cogeneration plant, in all other cases, ICE's, providing the best energy-related, economic and environmental performances, are the more suitable solution, even though CCPP's could appear interesting for industrial processes characterised by specific thermal consumption of about 200 $\mathrm{kWh} /$ ton and by production larger than 400,000 ton/year;

- Production processes, with medium heat requirement $\left(H_{\mathrm{CHP}} / E=1.0\right)$, specific thermal consumption in the range 100-1,300 $\mathrm{kWh} /$ ton and small/medium annual production, can be matched with cogeneration plants based on gas turbines and/or ICE's. When specific thermal consumption is in the range $750-3,000 \mathrm{kWh} / \mathrm{ton}$ and production is large, all cogeneration technologies are feasible: gas turbines and CCPP's appear to be the most beneficial solutions, ICE's, even though their performances are similar to those of GT's, could not be particularly appropriate, considering that the resulting plant size would involve the installation of multiple engines; 
- Production processes, with high heat requirement $\left(H_{\mathrm{CHP}} / E=2.0\right)$ and small/medium annual production, can be coupled with cogeneration plants based on GT's and/or ICE's, such solutions appear to be the only viable ones for industrial processes characterised by low specific thermal consumption $(100 \mathrm{kWh} / \mathrm{ton})$ and by large annual production. Industrial processes characterised by specific thermal consumption in the range $500-1,500 \mathrm{kWh} /$ ton and by large annual production can be coupled with all cogeneration technologies: GT's and/or ICE's appear to be the most beneficial solutions, also CCPP's can attain good performance when integrated in production processes with high demand for heat (specific thermal consumption of $1,500 \mathrm{kWh} / \mathrm{ton})$;

- Production processes, with very high heat requirement $\left(H_{\mathrm{CHP}} / E=3.0\right)$ and small/medium annual production, cannot be practically coupled with cogeneration plants, with the only exception of ICE's in the case of medium production, these industrial processes, with large annual production, can be matched with all cogeneration technologies, except for CCPP's: GT's, ICE's and SPP-BPT are the most appropriate solutions, SPP-CT could also be proposed, featuring, however, significantly worse energy, economic and environmental performances.

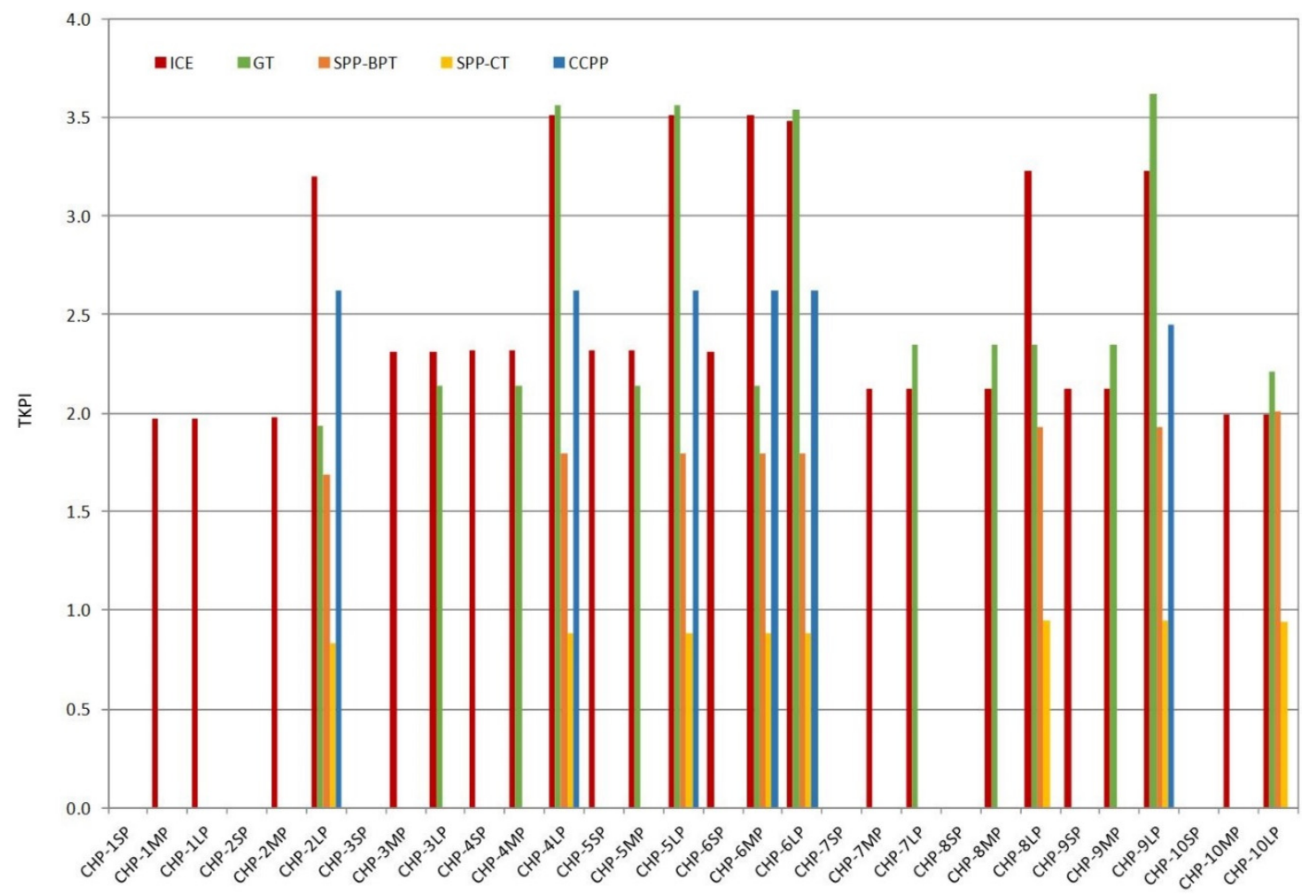

Figure 6. Total key performance indicator

\section{CONCLUSIONS}

In this paper, the technologies most suited to industrial sectors, significant in the CHP field, have been identified by using TKPI. By means of this indicator, each class of industrial processes has been matched with the best cogeneration technology, taking into account the specific thermal and electric consumptions along with annual production. The main findings of this analysis can be summarised as following:

- ICE's are a suitable solution for almost all industrial processes herein analysed and they attain the best performance when their size (electric power) is small, CCPP's are a suitable solution only in those industrial processes where heat demand is high and annual production is large; 
- SPP's are suitable solutions only in few industrial processes but, in comparison with other technologies, they attain worse energetic, economic and environmental performances.

Results of this work suggest a different sizing for CHP plants as compared to what had been usually done during the previous cogeneration regulatory context: in Italy, for instance, CHP plants were sized in order to produce the maximum possible electricity. In this new regulatory framework, instead, these power plants would not be competitive reason why many operators are evaluating modifications to current power plant set-up (for example, substitution of steam condensing turbine with back-pressure steam turbine). Even more so, the construction of a new cogeneration plant cannot disregard HEC regulatory context in which the selection and sizing of a CHP plant proves to be absolutely crucial.

\section{NOMENCLATURE}

CO\&M

$\mathrm{CO}_{2, \mathrm{a}}$

$C_{\mathrm{pp}}$

$C_{\mathrm{s}, \mathrm{E}}$

$C_{\mathrm{s}, \mathrm{H}}$

E

$E_{\mathrm{CHP}}$

$E_{\mathrm{CHP}} / E$

$F$

$F / E$

$F_{\text {CHP }}$

$F_{\mathrm{O \& M}}$

$H$

$H / E$

$H_{\mathrm{CHP}}$

$H_{\mathrm{CHP}} / E$

I

$N P V$

$N P V / I$

$P B P$

$P_{\mathrm{e}}$

$P_{\mathrm{t}}$

\section{Greek letters}

$\beta$

$\eta_{\mathrm{E}}$

$\eta_{\text {non-CHP,E }}$

\section{Abbreviations}

BoP

CCPP

$\mathrm{CHP}$

GT

HEC

HRSG

HT operation and maintenance costs

$\mathrm{CO}_{2}$ emissions avoided

power plant cost

specific electric demand

specific thermal demand

electricity

electricity from cogeneration

combined heat and power-electricity to electricity ratio

fuel input in a combined heat and power system

fuel energy to electricity ratio

fuel input to produce useful heat and electricity from cogeneration

percentage for operation and maintenance costs

heat

heat to electricity ratio

useful heat from cogeneration

combined heat and power-heat to electricity ratio

total investment

net present value

net present value to total investment ratio

pay-back period

electric power

thermal power

power loss factor by a heat extraction at a steam turbine

electric efficiency

efficiency of non-combined electrical/mechanical energy generation

Balance of Plant

Combined Cycle Power Plants with Condensing Turbine

Combined Heat and Power

Gas Turbine

High Efficiency Cogeneration

Heat Recovery Steam Generator

High Temperature 


$\begin{array}{ll}\text { ICE } & \text { Internal Combustion Engine } \\ \text { KPI } & \text { Key Performance Indicator } \\ \text { LS } & \text { Large Size } \\ \text { LT } & \text { Low Temperature } \\ \text { PES } & \text { Primary Energy Saving } \\ \text { SPP-BPT } & \text { Steam Power Plants With Backpressure Turbine } \\ \text { SPP-CT } & \text { Steam Power Plants With Condensing Turbine } \\ \text { SS } & \text { Small Size } \\ \text { TKPI } & \text { Total Key Performance Indicator }\end{array}$

\section{REFERENCES}

1. The Institution of Engineering and Technology (IET), Cogeneration: Technologies, Optimisation and Implementation (Frangopoulos, C. A., ed.), IET Digital Library, 2017.

2. International Energy Agency, World Balance 2015, https://www.iea.org/Sankey/, [Accessed: 25-June-2018]

3. Havelský, V., Energetic Efficiency of Cogeneration Systems for Combined Heat, Cold and Power Production, International Journal of Refrigeration, Vol. 22, No. 6, pp 479-485, 1999, https://doi.org/10.1016/S0140-7007(99)00010-9

4. Gambini, M. and Vellini, M., High Efficiency Cogeneration Part A: Regulatory Framework and General Calculation Procedures (in Italian), La Termotecnica, 2015.

5. Gambini, M. and Vellini, M., High Efficiency Cogeneration Part B: The Performance of Industrial Cogeneration Plants (in Italian), La Termotecnica, 2015.

6. Moreira, N. A., Monteiro, E. and Ferreira, S., Transposition of the EU Cogeneration Directive: A Vision for Portugal, Energy Policy, Vol. 35, No. 11, pp 5747-5753, 2007, https://doi.org/10.1016/j.enpol.2007.06.015

7. Frangopoulos, C. A., A Method to Determine the Power to Heat Ratio, the Cogenerated Electricity and the Primary Energy Savings of Cogeneration Systems after the European Directive, Energy, Vol. 45, No. 1, pp 52-61, 2012, https://doi.org/10.1016/j.energy.2011.12.044

8. Gvozdenac, D., Urosevic, B. G., Menke, C., Urosevic, D. and Bangviwat, A., High Efficiency Cogeneration: CHP and non-CHP Energy, Energy, Vol. 135, pp 269-278, 2017, https://doi.org/10.1016/j.energy.2017.06.143

9. Urošević, D., Gvozdenac, D. and Grković, V., Calculation of the Power Loss Coefficient of Steam Turbine as a Part of the Cogeneration Plant, Energy, Vol. 59, pp 642-651, 2013, https://doi.org/10.1016/j.energy.2013.07.010

10. Gambini, M. and Vellini, M., High Efficiency Cogeneration: Performance Assessment of Industrial Cogeneration Power Plants, Energy Procedia, Vol. 45, pp 1255-1264, 2014, https://doi.org/10.1016/j.egypro.2014.01.131

11. Gambini, M. and Vellini, M., High Efficiency Cogeneration: Electricity from Cogeneration in CHP Plants, Energy Procedia, Vol. 81, pp 430-439, 2015, https://doi.org/10.1016/j.egypro.2015.12.117

12. Kanoglu, M. and Dincer, I., Performance Assessment of Cogeneration Plants, Energy Conversion and Management, Vol. 50, No. 1, pp 76-81, 2009, https://doi.org/10.1016/j.enconman.2008.08.029

13. Verbruggen, A., High-Quality CHP: Definition, Measurement, and Regulation, Proceedings of the $11^{\text {th }}$ International Conference on Heat Transfer, Fluid Mechanics and Thermodynamics, Kruger National Park, South Africa, pp 338-343, 2015.

14. Monni, S. and Raes, F., Multilevel Climate Policy: The Case of the European Union, Finland and Helsinki, Environmental Science \& Policy, Vol. 11, No. 8, pp 743-755, 2008, https://doi.org/10.1016/j.envsci.2008.08.001 
15. Al-Mansour, F. and Kožuh, M., Risk Analysis for CHP Decision Making within the Conditions of an Open Electricity Market, Energy, Vol. 32, No. 10, pp 1905-1916, 2007, https://doi.org/10.1016/j.energy.2007.03.009

16. Li, M., Mu, H., Li, N. and Ma, B., Optimal Design and Operation Strategy for Integrated Evaluation of CCHP (Combined Cooling Heating and Power) System, Energy, Vol. 99, pp 202-220, 2016, https://doi.org/10.1016/j.energy.2016.01.060

17. Cho, H., Smith, A. D. and Mago, P., Combined Cooling, Heating and Power: A Review of Performance Improvement and Optimization, Applied Energy, Vol. 136, pp 168-185, 2014, https://doi.org/10.1016/j.apenergy.2014.08.107

18. Ropenus, S., Jacobsen, H. K. and Schröder, S. T., Network Regulation and Support Schemes - How Policy Interactions Affect the Integration of Distributed Generation, Renewable Energy, Vol. 36, No. 7, pp 1949-1956, 2011, https://doi.org/10.1016/j.renene.2010.12.015

19. Wolfrum, P., Kautz, M. and Schäfer, J., Smart Operation of CHP Units, IFAC Proceedings Volumes, Vol. 45, No. 21, pp 61-66, 2012, https://doi.org/10.3182/20120902-4-FR-2032.00013

20. Uday Kumar, N. T., Mohan, G. and Martin, A., Performance Analysis of Solar Cogeneration System with Different Integration Strategies for Potable Water and Domestic Hot Water Production, Applied Energy, Vol. 170, pp 466-475, 2016, https://doi.org/10.1016/j.apenergy.2016.02.033

21. Boyaghchi, F. A. and Heidarnejad, P., Thermoeconomic Assessment and Multi Objective Optimization of a Solar Micro CCHP Based on Organic Rankine Cycle for Domestic Application, Energy Conversion and Management, Vol. 97, pp 224-234, 2015, https://doi.org/10.1016/j.enconman.2015.03.036

22. Calise, F., Dentice D'Accadia, M., Vicidomini, M. and Scarpellino, M., Design and Simulation of a Prototype of a Small-scale Solar CHP System Based on Evacuated Flat-plate Solar Collectors and Organic Rankine Cycle, Energy Conversion and Management, Vol. 90, pp 347-363, 2015, https://doi.org/10.1016/j.enconman.2014.11.014

23. Isa, N. M., Tan, C. W. and Yatim, A. H. M., A Comprehensive Review of Cogeneration System in a Microgrid: A Perspective from Architecture and Operating System, Renewable and Sustainable Energy Reviews, Vol. 81, Part 2, pp 2236-2263, 2018, https://doi.org/10.1016/j.rser.2017.06.034

24. Hajabdollahi, H., Ganjehkaviri, A. and Jaafar, M. N. M., Assessment of New Operational Strategy in Optimization of CCHP Plant for Different Climates using Evolutionary Algorithms, Applied Thermal Engineering, Vol. 75, pp 468-480, 2015, https://doi.org/10.1016/j.applthermaleng.2014.09.033

25. Wang, J., Dai, Y. and Gao, L., Exergy Analyses and Parametric Optimizations for Different Cogeneration Power Plants in Cement Industry, Applied Energy, Vol. 86, No. 6, pp 941-948, 2009, https://doi.org/10.1016/j.apenergy.2008.09.001

26. Monte, M. C., Fuente, E., Blanco, A. and Negro, C., Waste Management from Pulp and Paper Production in the European Union, Waste Management, Vol. 29, No. 1, pp 293-308, 2009, https://doi.org/10.1016/j.wasman.2008.02.002

27. Posch, A., Brudermann, T., Braschel, N. and Gabriel, M., Strategic Energy Management in Energy-intensive Enterprises: A Quantitative Analysis of Relevant Factors in the Austrian Paper and Pulp Industry, Journal of Cleaner Production, Vol. 90, pp 291-299, 2015, https://doi.org/10.1016/j.jclepro.2014.11.044

28. Tamburini, A., Cipollina, A., Micale, G. and Piacentino, A., CHP (Combined Heat and Power) Retrofit for a Large MED-TVC (Multiple Effect Distillation along with Thermal Vapour Compression) Desalination Plant: High Efficiency Assessment for 
Different Design Options under the Current Legislative EU Framework, Energy, Vol. 115, Part 3, pp 1548-1559, 2016, https://doi.org/10.1016/j.energy.2016.03.066

29. Integrated Pollution Prevention and Reduction (IPPC), Legislative Decree 372/99 (Article 3, Paragraph 2), Guidelines for the Identification of the Best Available Techniques (in Italian), 2004.

30. Glass Industry, Integrated Pollution Prevention and Reduction (IPPC), Legislative Decree 372/99 (Article 3, Paragraph 2), Guidelines for the Identification of the Best Available Techniques (in Italian), 2007.

31. Food Industry, Integrated Pollution Prevention and Control (IPPC), Legislative Decree 372/99 (Article 3, Paragraph 2), Guidelines for the Identification of the Best Available Techniques (in Italian), 2008.

32. European Commission, Integrated Pollution Prevention and Control Reference Document on Best Available Techniques in the Food, Drink and Milk Industries, 2006.

33. White Paper on Milk and Dairy Products, Compedium (in Italian), 2006.

34. Ceramic Products, Integrated Pollution Prevention and Reduction (IPPC), Legislative Decree 372/99 (Article 3, Paragraph 2), Guidelines for the Identification of the Best Available Techniques (in Italian), 2007.

35. European Commission, Integrated Pollution Prevention and Control Reference Document on Best Available Techniques in the Ceramic Manufacturing Industry, 2007.

36. Oil and Gas Refineries, Integrated Pollution Prevention and Reduction (IPPC), Legislative Decree 372/99 (Article 3, Paragraph 2), Guidelines for the Identification of the Best Available Techniques (in Italian), 2007.

37. European Commission, Best Available Techniques (BAT) Reference Document for the Refining of Mineral Oil and Gas Industrial Emissions Directive 2010/75/EU (Integrated Pollution Prevention and Control), 2015.

38. U.S. Environmental Protection Agency (U.S. EPA), Office of Air and Radiation, Available and Emerging Technologies for Reducing Greenhouse Gas Emissions from the Iron and Steel Industry, 2012.

39. Worrell, E., Blinde, P., Neelis, M., Blomen, E. and Masanet, E., Energy Efficiency Improvement and Cost Saving Opportunities for the U.S. Iron and Steel Industry, An ENERGY STAR ${ }^{\circledR}$ Guide for Energy and Plant Managers, Environmental Energy Technologies Division, Ernest Orlando Lawrence Berkeley National Laboratory, University of California, Berkeley, USA, 2010, https://doi.org/10.2172/1026806

40. U.S. Environmental Protection Agency (U.S. EPA), Office of Compliance Sector Notebook Project, Profile of the Rubber and Plastics Industry ( $2^{\text {nd }}$ Edition), EPA/310-R-05-003, 2005.

41. U.S. Environmental Protection Agency (U.S. EPA), Office of Policy, Economics, and Innovation Sector Strategies Division, Energy Trends in Selected Manufacturing Sectors: Opportunities and Challenges for Environmentally Preferable Energy Outcomes, 2007.

42. VGB PowerTech, Levelised Cost of Electricity (LCOE 2015), VGB-B 031, https://www.vgb.org/en/lcoe2015.html?dfid=74042, 2015, [Accessed: 25-June-2018]

43. International Energy Agency (IEA), Combined Heat and Power - Evaluating the Benefits of Greater Global Investment, 2008.

44. U.S. Energy Information Administration (EIA), Capital Cost Estimates for Utility Scale Electricity Generating Plants, 2016.

45. U.S. Environmental Protection Agency (EPA), Combined Heat and Power Partnership, Catalog of CHP Technologies, 2017.

46. Regulatory Authority for Energy Networks and the Environment (ARERA), Annual Report on the Status of Services and Activity Carried Out (in Italian), 2017. 
47. Confindustria Centro Studi, In Italy Manufacturing Shrinks, in the Advanced Countries, Industrial Policies are Focused on the Territory (in Italian), SIPI S.p.A., 2014.

48. Istituto Nazionale di Statistica (ISTAT), Report on the Competitiveness of the Productive Sectors, edition 2014.

Paper submitted: 24.03 .2018

Paper revised: 25.06 .2018

Paper accepted: 01.07.2018 